\title{
Agent-Based Simulation of Children's School Travel Mode with Parental Escort Decisions
}

\author{
Peng Jing *, Qingku You and Long Chen \\ School of Automotive and Traffic Engineering, Jiangsu University, Zhenjiang 212013, China; \\ 18852867273@163.com (Q.Y.); chenlong@ujs.edu.cn (L.C.) \\ * Correspondence: jingpeng@ujs.edu.cn; Tel.: +86-159-5140-6967
}

Received: 8 February 2018; Accepted: 24 February 2018; Published: 28 February 2018

\begin{abstract}
In the last few years, the number of private cars has expanding quickly in China, more and more parents use cars to escort their children to school, thus cause serious traffic congestions near school in many cities. In this paper, we developed an agent-based model (ABM) of the parents' choice of escort mode. The core of this model is an escort mode choice motivation adjustment function that combines distance, traffic safety and social influence. We also used ABM to exhibit the emergent decoy effect phenomenon, which is a dynamic phenomenon that the introduction of a decoy to the choice-set could increase the share of other alternatives. The model reveals the parents' inner psychological mechanism when facing competing escort mode choice in transportation system. The simulation results show that the proportion of parents to choose bus escort was $62.45 \%$ without the decoy effect was introduced, while the proportion of parents to choose bus escort increased to $74.29 \%$ with the decoy effect was entry. The use of the ABM method gives the potential to cope with the dynamic changes in studying parent escort mode choice behavior.
\end{abstract}

Keywords: agent-based model; children; parental escort decision; school travel mode; decoy effect

\section{Introduction}

A great deal of research in the field of travel-demand modeling has focused on analyzing the adult travel behavior. In contrast, there are relatively few studies on the modeling of children's travel behavior. In fact, not all household travel surveys collect detailed travel information about children. Yet, a comprehensive understanding of travel patterns for children is becoming increasing important to transportation and urban planners [1].

The focus of this study is school travel, which is an important part of children's daily travel behavior. Specifically, we examine the children's mode choice with parental escort decisions. The need to understand these mode choice decisions is gaining importance because of various perspective.

From the personal perspective, the decline in physical activity levels and the corresponding increase in obesity of school children over the past few decades have aroused concerns [2]. Regular exercise in children and adolescents is an important basis for the formation of good physical quality and mental health. Active school travel (walking or cycling) is considered to be an effective way of physical exercise. Frequent use of active school travel is beneficial to the intellectual, physical and psychological development of primary and secondary school students [3,4]. However, the increase in the use of cars in school travel resulted in a decrease in the proportion of active school travel modes for student, which means reducing the opportunity for a student to exercise, and increasing the risk of obesity among children. In order to reverse the downward trend in active school travel and to reduce the negative impact of the high proportion of cars on school trips. Only by accurately locating and deeply understanding of various factors affecting the school travel mode choice behavior can we scientifically and reasonably formulate sustainable and effective guiding policies and measures 
to reduce the proportion of parents choosing cars to escort their children to school. From the family perspective, as children are significantly dependent on their parents for mobility. Thus, realistic travel-demand forecasts and policy evaluation require capture children-parent interactions [5]. In addition, because of the poor active travel environment and traffic safety, it is more common for parents to escort their children to school. A full understanding of children's school choices can help traffic administrative department formulate reasonable policies and guide parents to use non-motor vehicles to escort their children. And then the associated travel demand can be reduced and the travel cost can be saved. From the social perspective, the school-going population has been increasing over the past two decades. In this context, parental escorts, especially the use of car escorts, have resulted in severe traffic congestion around the school. Not only has the capacity of road traffic been declined, but also the access environment of school gate is affected negatively [6]. Take Beijing as an example, in the morning peak period, the traffic congestion index around the school was 6 to 9 , indicating that moderate congestion and serious congestion. In contrast, in the other time period, the traffic index around the school was 3 to 6 , indicating that congestion was basically smooth and slightly congested [7]. If we can have a deep understanding of the student's school travel mode and accurately predict the composition and flow size of the trip, we can make more reasonable investment and transformation to the infrastructure and transportation services around the school. And formulate scientific policies and measures to guide the school travel mode choice, and reduce the proportion of parents to choose car escort their children to school. The broad objective of research school mode choice is to contribute toward encourage sustainable transport modes alleviating localized congestion near schools, and eventually support the sustainable development of the society.

With a significant increase in the number of parents use car escort children to school, more and more articles are concerned about the problem of the children's school travel mode choice with parental escort decisions [8]. Table 1 summarizes the previous studies, which are selected to cover main characteristics of studies including children sample, sample size, methodology, and travel modes.

From the influential variable side, these factors are broadly classified into four categories: children's characteristics, parents' characteristics, built environment, and parental concerns.

Among the characteristics of the child. Ermagun and Samimi [9] reported a positive correlation between age and using active modes of travel. Zwerts and Wets [10] revealed that children's age has a strong influence on the mode choice. Specifically, older children are more likely to use non-auto modes such as walk, bike, transit, and school bus. Nelson et al. [11] stated that girls are found to be less use public transport but more likely to be driven.

The next set of factors is the parents' characteristics. He et al. [5] studied the choice of escorts for students aged 5-8 in the Los Angeles area. The findings show that mother who increased working hours and more distant job locations are less likely to chauffeur their children. Mehdizadeh et al. [12] found that parent perceived walking time to school had a random effect on mode choice. Ermagun and Samimi [9] pointed out that parents' income was recognized in school trip active modes of transportation utilization. Hsu et al. [13] used binary logit model and multinomial logit model shown that parental gender and attitudes influence on parental escort behavior and children's school travel mode.

The next set of factors relates to the characteristics of built environment. Mehdizadeh et al. [12] revealed that parents with stronger environmental personal norms were more likely to choose walking mode for their children. Liu et al. [14] applied the logistic regression models to predict the probability that who pick up child on a normal workday and in two hypothetical emergencies situation. The findings suggest that increasing the distance between parents and children decreased the likelihood of parents picking up children in a normal weekday. In an emergency, distance has a greater impact on mothers picking up a child, but not significant for father. Nelson et al. [11] concluded that distance is an important perceived barrier to active commuting, and it is observed that $2.5 \mathrm{~km}$ is a guiding "splitting line" between the active travel modes and motorized. Looking into the parental concerns. Mehdizadeh et al. [12] reported that parental risk judgements, transport safety attitudes, 
transport priorities and accident experiences were important for mode use among children. They found parental risk judgements, accident experiences and transport priorities were negatively related to children's walking to school. The more convenient the traffic is, the more likely the parents are to allow their children to walk to school. Ermagun and Levinson [15] developed two separate three level nested logit models explore school escort decisions with a few policy sensitive variables. The results found that parent safety concerns had a negative role on active travelling to school. Susilo et al. [16] adopt structural equation model confirm that parents' safety perceptions influence on their children travel mode.

Table 1. List of previous studies on school travel mode choice with parental escort.

\begin{tabular}{|c|c|c|c|c|}
\hline Citation & Children Sample & Sample Size & Method & Travel Modes \\
\hline He et al. (2017) & Age 5-18 years old & 3169 & Multinomial logit & $\begin{array}{l}\text { Active commuting, } \\
\text { bus, car }\end{array}$ \\
\hline $\begin{array}{l}\text { Mehdizadeh et al. } \\
\text { (2017) }\end{array}$ & Age 7-9 years old & 735 & Mixed logit model & $\begin{array}{c}\text { School service modes, } \\
\text { household private cars, } \\
\text { motorcycles, walking } \\
\text { and buses. }\end{array}$ \\
\hline $\begin{array}{l}\text { Ermagun et al. } \\
\text { (2016) }\end{array}$ & Age 6-18 years old & 1737 & $\begin{array}{l}\text { Multitude of } \\
\text { statistical }\end{array}$ & $\begin{array}{l}\text { Active, auto, public } \\
\text { transit, school bus }\end{array}$ \\
\hline $\begin{array}{l}\text { Ermagun et al. } \\
\text { (2016) }\end{array}$ & Age 6-18 years old & 3441 & $\begin{array}{c}\text { Three-level nested } \\
\text { logit }\end{array}$ & $\begin{array}{l}\text { Active, car, public } \\
\text { transport }\end{array}$ \\
\hline Susilo et al. (2016) & Age 5-15 years old & 30,645 & $\begin{array}{l}\text { Structural equation } \\
\text { modelling }\end{array}$ & $\begin{array}{l}\text { Active, car, public } \\
\text { transport }\end{array}$ \\
\hline Hsu et al. (2014) & Age 5-15 years old & 729 & $\begin{array}{l}\text { Binary logit model } \\
\text { Multinomial logit } \\
\text { model }\end{array}$ & Active commuting \\
\hline Liu et al. (2012) & Age 6-18 years old & 183 & Binary logit mode & Active commuting \\
\hline Nelson et al. (2008) & Age $15-17$ years old & 4013 & $\begin{array}{l}\text { bivariate logistic } \\
\text { regression }\end{array}$ & Active commuting \\
\hline $\begin{array}{l}\text { Zwerts and Wet } \\
\text { (2006) }\end{array}$ & Age $10-13$ years old & 2482 & Cluster analysis & Active commuting \\
\hline
\end{tabular}

As shown in Table 1, from the methodological point of view, research on children's school travel with parental escort decision usually used traditional economic models such as multinomial logit, nested logit, multitude of statistical and structural equation modelling. Such models determine the structure of relationships between variables and use empirical data to estimate the model parameters [17]. However, these are typically static models, representing a system at a particular point in time. It is difficult to use this type of model to test subtle variations in behavior in a dynamic way. In contrast, $\mathrm{ABM}$ is particularly relevant when complex relationships are dynamic, when dynamic information is available, or when there is not enough specific data available for using an econometric approach [18]. In addition, ABM paradigm provides tools to study inter-linkages (e.g., between parents) using behavioral rules unlike statistical methods where each dataset is looked at in isolation. ABM can be used to conduct various "what-if" experiments deal with dynamic systems change [19]. Which offers many advantages compared with conventional approaches in traffic simulation. It is worth noting that there are few studies on children's school travel based on ABM. For example, Yang et al. [19] developed an agent-based model to simulate exploring how various policies influence children's school travel behavior within a hypothetical city. Yang's work in particular is notable due to the attention paid on application of agents in the travel behaviors [20,21].

Motivated by the above discussion, to our knowledge, applications of ABM to the study children's school travel mode behavior remains limited, and has not yet focused on parental escort with psychological factors. 
The remainder of this paper is organized as follows: Section 2 explains the development of the agent-based model of the school travel mode with parental escort decisions. Section 3 presents the data and sample characteristics. Section 4 presents simulation experiments and analysis of these experiments results. Finally, conclusions and offer suggestions for further research are presented in Section 5 .

\section{An Agent-Based Model of the School Travel Mode with Parental Escort Decisions}

\subsection{The Theoretical Framework for the School Travel Mode with Parental Escort}

Decision-making is a complex cognitive process involving perception, learning and information processing. As Ajzen et al.'s model (Figure 1) shows, most of personal behavior are planned behaviors [22]. A central factor in the theory of planned behavior is the intention of an individual to perform a given behavior. Intentions are assumed to capture the motivational factors that influence a behavior. Attitude, subjective norm, and perceived behavioral control are key drivers for building intentions. Each of these factors is driven by beliefs: beliefs about the consequences, social perceptions, and one's own capability [23]. McClelland [24] divides intentions into two categories: conscious intention and unconscious intention, while also suggesting that motivation is the reflection of the conscious intention.

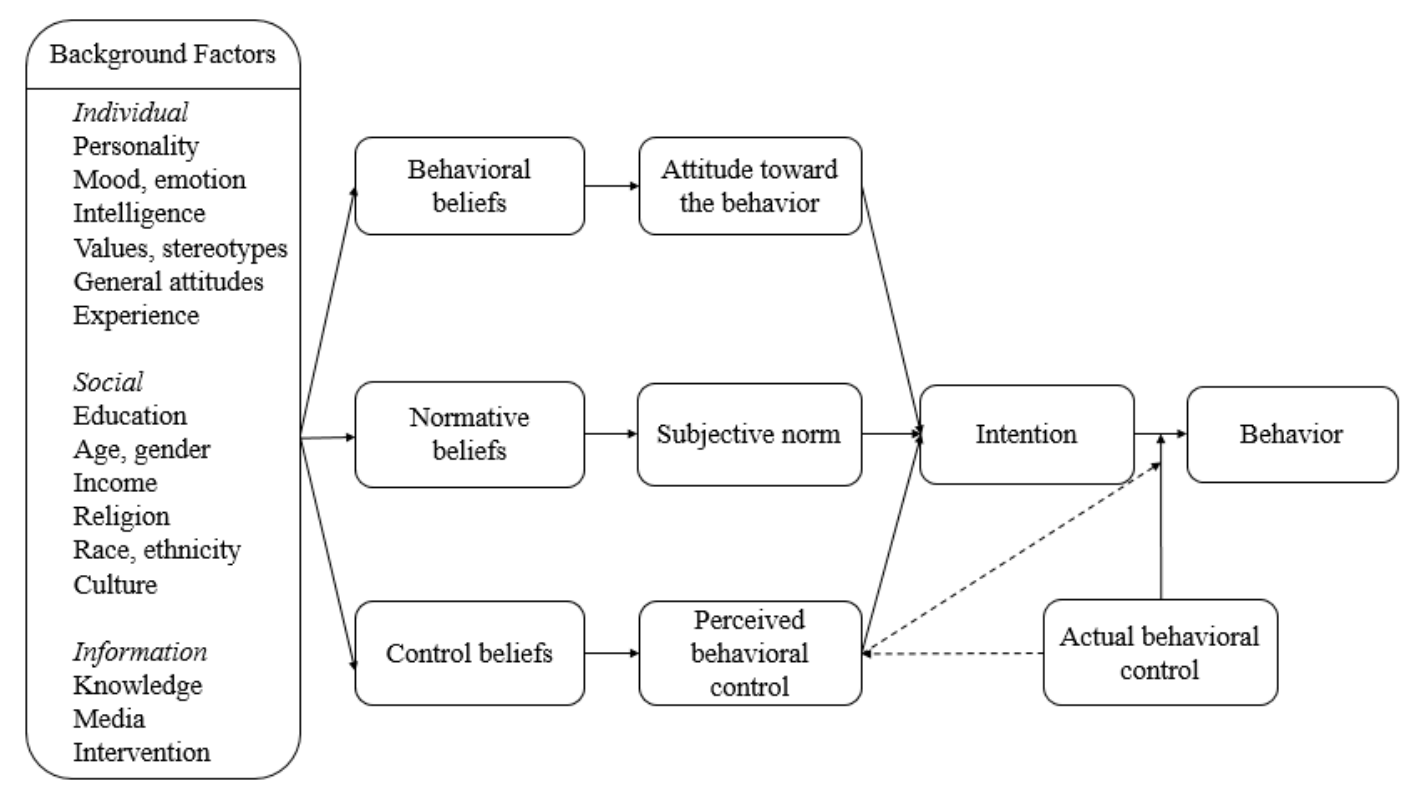

Figure 1. The theory of planned behavior.

\subsection{The Escort Mode Choice Motivation Model}

Most of the escort decisions are planned behaviors. Therefore, intention in the escort decision-making process refers to conscious intention, and one can consider motivation as the direct determinant of the escort decision. The key stimuli that lead parents to make their escort decisions in the complex transportation environment are travel cost, travel time, social influence and perception of parents' traffic safety. The parent's personality traits determine how these external stimuli affect him/her. Therefore, as shown in Figure 2, the escort motivation decision model consists of three parts: external stimuli, personality traits, and motivation. 


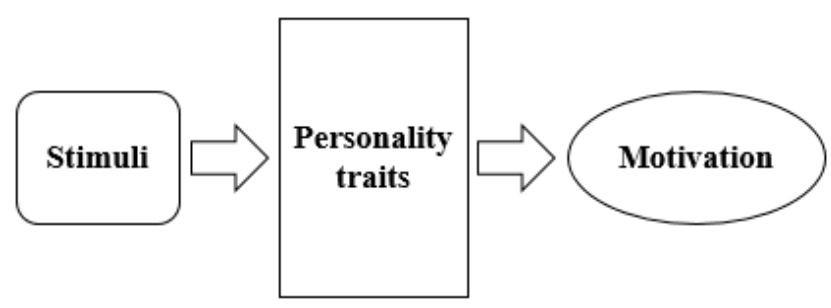

Figure 2. The escort mode choice motivation model.

\subsection{The Escort Mode Choice Decision Model}

Before constructing the model, the assumption has to be that parents make escort mode choice based on logical decisions, which is in line with the planned behavior and conscious intention theories. From this perspective, each parent is an agent, which has an own personality traits and their socio-economic interactions. There are two types of agents, one is parent agent and the other is neighbor agent. The child is not regarded as an independent agent. The reason is, for the younger children, they do not have the ability to be autonomous. For the older children, they are pushing very hard to be more autonomous, parents tend to be protective because of their perception of the risks and dangers in e.g., public space (social risks, safety risks) while children don't consider them to be real risks. The inconsistencies between parents and children may have an influence on escort mode choice.

According to consumer behavior theory, choice behavior is determined by explicit variable factors and latent variable factors, school travel mode choice is also a kind of special commodity consumption behavior [25]. Thus, school travel mode choice also accorded with consumer behavior theory. The key stimuli that influence on the agent's motivation to make their escort decisions are combination of explicit and psychological variable factors. Socio-demographic characteristics, distance to school concretely are explicit variable factors. Traffic safety and social influence are psychological factors. These factors will be separate detail discussed below.

For explicit variable factors, the agent's socio-demographic attributes such as age, income, educational level, and professional status, may greatly influence the agent's personality traits. For example, household income is major predictor of school travel choice with highly significant and large coefficients in households' characteristics. Students from low-income families are typically found to travel alone and most likely to use the non-car modes, due to high income families have easier access to personal vehicle [9]. Simultaneously, the distance from home to school could be seen as a built environment attribute, which also influence the agent's personality traits. Long distance between home and school is the most common barrier to independent travel to school.

For psychological factors, traffic safety is important component in the escort decision and it is also another major barrier to independent travel to school. Parental concern about dangerous traffic were associated with children's active commuting behavior [26]. For example, if parents perceive higher accident risk probability and severity of consequences when their children are walking to school, they are more likely to choose private car instead of bus as escort mode. In addition to traffic safety, many behavioral economists and psychologists framed that "social choice", and points out that the individual decision is inevitably influenced by others' actions [27]. McFadden further explained "social choice", he believed that the travel mode choice is influenced by the behavior of others, attitudes and beliefs of homogeneous groups, and the individual's perceptions of these [28]. Social influence, the process of having one's behavior be affected by others. The role of social influence in students' escort behaviors deserve more investigation. Therefore, we employ social influence variables to capture students' escort behaviors interdependence.

The stimuli derived from the above four factors have a great influence on the parent agent's escort mode choice motivation. Each stimulus' contribution to the parent agent's escort mode choice motivation is calibrated by the parent agent's relevant personality trait. Therefore, based on the stimuli related to the four factors, one can derive their relevant personality traits, namely travel time 
sensitivity, travel cost sensitivity, distance sensitivity, social influence, and perceived safety. The parent agent's escort mode choice decision model as shown in Figure 3. Stimuli was represented by the dotted rectangle.

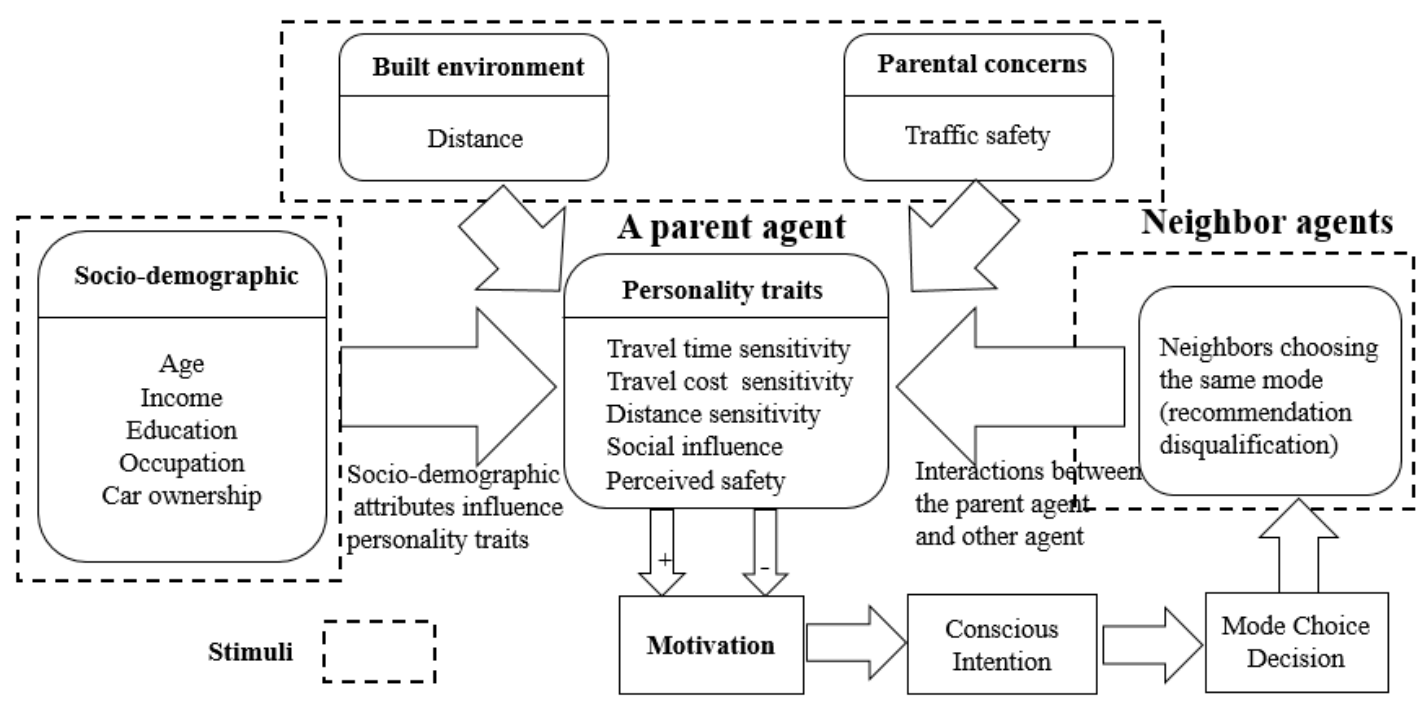

Figure 3. The parent agent's escort mode choice decision model.

\subsection{The Escort Mode Choice Motivation Adjustment Function}

In our paper, the two main types of agents are parent agent and neighbor agent. As shown in Figure 3, in the parent agent's escort mode choice decision model the stimuli are the independent variables. Once a parent agent has perceived these independent variables, parent agent will be form a corresponding motivation in line with parent agent relevant personality traits. With different school mode, the parent agents will achieve different levels of escort mode choice motivation. The preferred choice is the one that can bring the parent agent the largest degree of motivation. Parental escort decision-making is a cognitive process in which the stimuli and personality traits can be defined by certain algorithms, is as shown below:

$$
M_{n i}=T_{s i} T_{i}+C_{s i} C_{i}+P_{D} D+S_{\text {saftey }}+S_{\text {si }} S_{\text {social }}
$$

$M_{n i}$ is the motivation of mode $i$ ( $i=1$ to 2 , respectively indicate car and bus) of a parent agent $n$. $T_{S i}$ is the parent agent's travel time sensitivity parameter from home to school mode choice $i$. $T_{i}$ is the travel time from home to school by mode $i ; C_{S i}$ is the parent agent's travel cost sensitivity parameter from home to school by mode $i . C_{i}$ is the travel cost from home to school by mode $i ; P_{D}$ is the probability of escorting travel to school given the distance to the school. $D$ is the distance from home to school; $S_{s a f t e y}$ is a level of concern towards traffic safety of mode $i$. $S_{s i}$ is the parent agent's social influence sensitivity parameter perceived influence exerted by other neighbor agents; $S_{\text {social }}$ is the perceived social influence exerted by other neighbor agents.

Escort mode choice motivation adjustment function are implemented through updates to each persons' motivation toward school travel mode in the subsequent day. The first part in the mode motivation adjustment function is travel time utility section. Each travel time $T_{i}$ can trigger a travel time sensitivity $T_{s i}(i=1$ to 2 ). Parent agent's travel time sensitivity is an exponential function of the difference between the real travel time of the mode $i$ and the expected travel time of the mode $i$. When a parent agent chooses a mode, the closer the travel time of the mode approximates the parent agent's expected travel time of mode, the more travel time sensitivity. The parent agent's travel time sensitivity mathematical formula is:

$$
T_{s i}=-\delta^{T_{i}-T_{e}}+t
$$


where $\delta$ is a parameter and $0<\delta<1, t$ is a constant which value of $t$ is based on parent agent's socio-economic attributes, and $T_{e}$ is the parent agent's expected travel time of this type of mode $i$.

$$
T_{e}=T_{\text {ave }}=\frac{1}{N} \sum_{i=1}^{N} T_{\mathrm{i}}
$$

where $N$ is the number of mode agent, $T_{i}$ is the travel time of mode $i$, and $T_{\text {ave }}$ is the average travel time of all modes, based on Equations (3) and (4), the result is:

$$
T_{s i}=-\delta^{c_{i}-c_{a v e}}+t
$$

The second part in the mode motivation adjustment function is travel cost utility section. The parameter of the parent agent's travel cost sensitivity $C_{s i}$ is the coefficient of the stimulus $C_{i}$. Each travel cost $C_{i}$ can trigger a travel cost sensitivity $C_{s i}(i=1$ to 2$)$. Parent agent's travel cost sensitivity is an exponential function of the difference between the real travel cost of a mode $i$ and the expected travel cost of the mode $i$, as shown in Equation (5).

$$
C_{s i}=-\lambda^{c_{i}-c_{e}}+c
$$

where $\lambda$ is a parameter and $\lambda>1, c$ is a constant which value of $c$ is based on parent agent's socio-economic attributes, and $C_{e}$ is the parent agent's expected travel cost of this type of mode.

$$
C_{e}=C_{\text {ave }}=\frac{1}{N} \sum_{i=1}^{N} C_{\mathrm{i}}
$$

where $N$ is the number of mode, $C_{i}$ is the travel cost of mode $i$, and $C_{\text {ave }}$ is the average travel cost of all modes, based on Equations (5) and (6), the result is:

$$
C_{s i}=-\lambda^{c_{i}-c_{a v e}}+\mathrm{c}
$$

The third part in the escort mode choice motivation adjustment function is distance utility section. Distance sensitivity is an analysis of distance elasticity based on the monetary, utilitarian, and emotional value that parent agent escort decision. $P_{d}$ is the probability of escorting travel to school given the distance to the school. $P_{d}$ is computed as follows:

$$
P_{D}=e^{-\beta D}
$$

where $D$ is the distance from household to school and $\beta$ is the distance sensitivity parameter.

The fourth part is traffic safety utility section, each parent agent has a level of concern towards traffic safety (denoted by $C_{\text {safety }}$ ). $C_{\text {safety }}$ is a threshold value: if traffic safety is perceived to be above that value, the parent agent may allow the child independent travel to school. $C_{\text {safety }}$ remains constant. Each day, children travel to school independently or are escorted by their parents. If the mean traffic safety from household to school above the parent agent's concern towards traffic safety, child will be escort by their parents.

$$
S_{\text {safety }}>C_{\text {safety }}
$$

where $S_{\text {safety }}$ is the mean traffic safety from household to school. $C_{\text {safety }}$ is the parent agent's concern towards traffic safety.

For a given parent agent, although the distance from the household to the school is assumed to be constant over time, the escort mode choice may differ. $S_{\text {safety }}$ is updated daily, each day the traffic safety is updated as a function of the total number of parent agent who drive the car escort child to school as follows:

$$
S_{\text {safety }}=S_{s} \times\left(1-S^{-0.6}\right)
$$


where $S_{S}$ is safety effectiveness parameter and $S$ is the total number of parent who drive the car escort child to school.

The fifth part is social influence utility section, many behavioral economists and psychologists noted that "social choice", that is, an individual's decisions are not immune from the influence of others. For a parent agent $P$, the attitude is influenced by the attitudes of neighbor agent $F$ in their social network as:

$$
S_{\text {social }}(P)=C R \times S_{\text {social }}(F)
$$

where $S_{\text {social }}(F)$ represents the percentage of parent agent who use this mode in contact with neighbor agent in their social network, $C R$ represents average daily interaction rate.

In order to highlight the travel time-cost trade-off during the decoy effect. Combining the Equations (2), (5), (8), (9) and (11), the formula of escort mode choice motivation adjustment function is:

$$
\begin{aligned}
M_{n i}= & \left(-\delta^{T_{i}-T_{e}}+t\right) \times T_{i}+\left(-\lambda^{c_{i}-c_{e}}+c\right) \times C_{i}+e^{-\beta D} \times D+S_{s} \times\left(1-S^{-0.6}\right) \\
& +C R \times S_{\text {social }}(F)
\end{aligned}
$$

So a parent agent's final choice decision is based on the algorithm: $\max \left\{M_{n 1}, M_{n 2}, M_{n 3}, \ldots, M_{n i}\right\}$.

\section{Data}

\subsection{Questionnaire}

In order to calibrate the model, the data collection was carried out in March 2017 by a cross-sectional questionnaire survey in Zhenjiang, China. The questionnaire survey aimed to understand motivation factors influence on preferences regarding parent escort mode. The questionnaire survey consisted of two parts, as shown in Table 2. The first part is revealed-preference (RP) survey which contained the attributes of individual, school and household. The second part is the survey about psychological factors. Investigating the primary escort travel modes in which their child had travelled to school in the past week. Two mode alternatives were identified for each of travel to school. These are (1) car, (2) bus. A team of trained field workers visited each school to distribute questionnaires for parents and parents according to standard operating procedures to complete the questionnaire.

The attributes of household included parental age, parental gender, parental education status, parental occupation, income of the parental per month, the number of cars owned by households, children' gender, parental driving license status, distance from home to school.

Transport safety and social influence were included in the psychological factor part. Parents were asked about their agreement with two statements regarding their attitude towards their child's journey to school transport safety, such as: "How do you feel about the security of the various escort mode?", "The security of the escort is your primary concern". Their level of agreement on such statements on a five-point Likert scale ranging from (1) "strongly disagree" to (5) "strongly agree". Parents' perceptions of social influence from friends and parents were assessed using several questions. "The influence of your friend on the choice of your escort?", "The influence of your family on the choice of your escort?". The parents rated social influence levels on a five-point Likert scale ranging from (1) "strongly disagree" to (5) "strongly agree".

In total, 270 distributed questionnaires were returned. Through the data processing, the data of the explicit variable attributes and psychological factors variables of the sample which are missing or not meet the requirements are deleted. Finally, only questionnaires without missing fields $(n=245)$ were taken into further analysis. 
Table 2. Variables used in the questionnaire.

\begin{tabular}{|c|c|c|}
\hline Variable & Measure & Scale or Response Category \\
\hline Explicit variable & $\begin{array}{c}\text { Children characteristics } \\
\text { Children's gender } \\
\text { School grade of the children } \\
\text { Children's age } \\
\text { Parental age } \\
\text { Parental gender } \\
\text { Parental education status } \\
\text { Parental occupation } \\
\text { Income of the whole household per month } \\
\text { The number of cars owned by households } \\
\text { Parental driving license status } \\
\text { School characteristics } \\
\text { Distance from home to school } \\
\text { Parental perceived travel cost from home to school } \\
\text { Parental perceived travel time from home to school } \\
\text { Primary escort modes } \\
\text { Bus, car }\end{array}$ & $\begin{array}{c}\text { - } \\
2 \text { Alternatives } \\
\text { Continuous variable } \\
\text { Continuous variable } \\
\text { - } \\
5 \text { Alternatives } \\
2 \text { Alternatives } \\
5 \text { Alternatives } \\
6 \text { Alternatives } \\
5 \text { Alternatives } \\
\text { Continuous variable } \\
\text { Yes/no } \\
\text { - } \\
4 \text { Alternatives } \\
\text { Continuous variable } \\
\text { Continuous variable } \\
\text { - } \\
2 \text { Alternatives }\end{array}$ \\
\hline Psychological factors & $\begin{array}{l}\text { Travel safety } \\
\text { Perceived safety from the home to school } \\
\text { Social influence } \\
\text { How do you feel about the security of the various escort mode? } \\
\text { The security of the escort is your primary concern? } \\
\text { The influence of your friend on the choice of your escort? }\end{array}$ & $\begin{array}{l}5 \text { point-Likert scale, strongly disagree to strongly agree } \\
5 \text { point-Likert scale, strongly disagree to strongly agree } \\
5 \text { point-Likert scale, strongly disagree to strongly agree } \\
5 \text { point-Likert scale, strongly disagree to strongly agree }\end{array}$ \\
\hline
\end{tabular}




\subsection{Sample Characteristics and Descriptives}

The sample consisted of $43.41 \%$ parents of male and $56.59 \%$ parents of female. A total of $43.84 \%$ of the respondents had a private car and $56.16 \%$ of parents had no private vehicle. A total of $51.22 \%$ (n $=126)$ of parents had a driving license and $48.78 \%(n=119)$ of parents without driving license. Of the 245 respondents who answered these questions, $45.85 \%$ live within 2 miles from school and $18.05 \%$ live beyond 4 miles. $48.32 \%$ of children were driven to school, $23.50 \%$ used electric bike, $12.36 \%$ walked or biked, and $16.82 \%$ used bus. Moreover, $57.23 \%$ of children who went to school by car on their survey day were chauffeured by their parent who was surveyed. These numbers show a very low parental escort rate for non-automobile trips. These differences in trip length are likely to affect the choice of mode of travel to school for the different age groups. Table 3 shows descriptive statistics for explicit variables and a short description for each variable used in the study.

Table 3. Explicit variables used in the study.

\begin{tabular}{|c|c|c|c|c|c|}
\hline Variable & Description & Mean & SD & Min & Max \\
\hline Children gender & Boy $=1$, girl $=2$ & 1.63 & 0.54 & 1 & 2 \\
\hline School grade of the children & Continuous variable & 5.62 & 1.36 & 1 & 9 \\
\hline Children's age & Continuous variable & 9.71 & 1.77 & 1 & 15 \\
\hline Parental age & $\begin{array}{c}20<\text { age } \leq 25 \text { Age }=1 \\
26<\text { age } \leq 30 \text { Age }=2 \\
31<\text { age } \leq 35 \text { Age }=3 \\
36<\text { age } \leq 40 \text { Age }=4 \\
>40 \text { Age }=5\end{array}$ & 2.70 & 1.25 & 1 & 5 \\
\hline Parental gender & Male $=1$, Female $=2$ & 1.56 & 0.49 & 1 & 2 \\
\hline Parental education status & $\begin{array}{l}\text { Primary school }=1 \\
\text { Junior school }=2 \\
\text { High school }=3 \\
\text { Undergraduate }=4 \\
\text { Graduate }=5\end{array}$ & 2.89 & 1.15 & 1 & 5 \\
\hline The number of cars owned by households & Continuous variable & 1.53 & 0.46 & 0 & 3 \\
\hline Parental driving license status & $\mathrm{Yes}=1, \mathrm{No}=2$ & 1.48 & 0.50 & 1 & 2 \\
\hline Distance from home to school & $\begin{array}{c}<0.5 \text { Dis }=1 \\
0.5<\mathrm{d} \leq 2 \text { Dis }=2 \\
2<\mathrm{d} \leq 4 \text { Dis }=3 \\
>4 \text { Dis }=4\end{array}$ & 2.54 & 1.32 & 1 & 4 \\
\hline Parental perceived travel cost from home to school & Continuous variable & 5.36 & 1.20 & 1 & 10 \\
\hline Parental perceived travel time from home to school & Continuous variable & 8.62 & 5.27 & 1 & 20 \\
\hline
\end{tabular}

SD: Standard deviation. Min: Minimum, Max: Maximum.

\section{Agent-Based Model of the School Travel Mode with Parental Escort Decisions}

\subsection{The Decoy Effect}

If two travel modes are available in transportation system, bus and car, travelers have to make a choice between the two travel modes. Suppose that the alternatives are only described by their travel time and travel cost and that it takes $45 \mathrm{~min}$ to reach the destination by Bus and $30 \mathrm{~min}$ by Car. In contrast, the fare of the Bus is $0.5 ¥$, and the cost of the Car is $5 ¥$. These alternatives are illustrated in Figure 4.

To encourage more parents to shift from car to bus to escort children to school. Now, the $(45,0.5)$ Bus option can only be selected by the holders of a "bus card" (BC) and the price for other parents in the same bus becomes 1¥. This new fare scheme is illustrated in Figure 5. Since the BC is free, it will be used in practice by all interested parents. Thus, almost nobody would choose the Bus option $(45,1)$. However, according to the decoy effect, the introduction of the unattractive alternative $(45,1)$ 
would result in an increase of the share of the original Bus option $(45,0.5)$, compared to the Car. In this example, $(45,0.5)$ is the Objective $(\mathrm{O})$ alternative, $(45,1)$ is the Decoy $(\mathrm{D})$ alternative and $(30,5)$ is Competitor $(\mathrm{C})$ alternative. As shown in Figure 6.

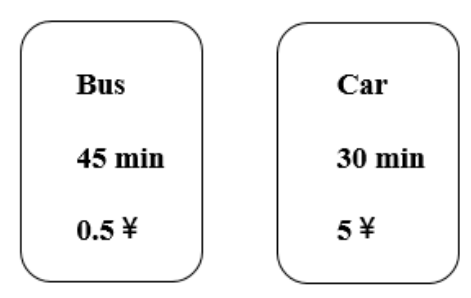

Figure 4. Bus versus car example with no decoy alternative.

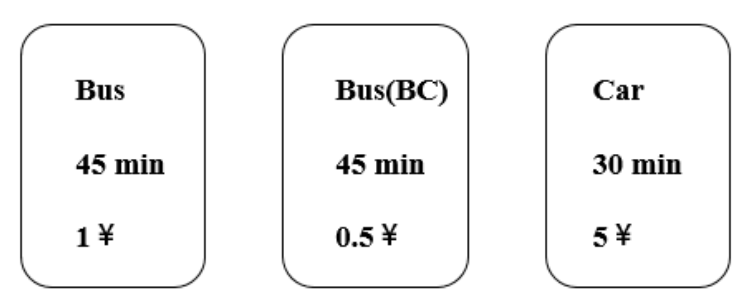

Figure 5. Bus versus car example including decoy alternative.

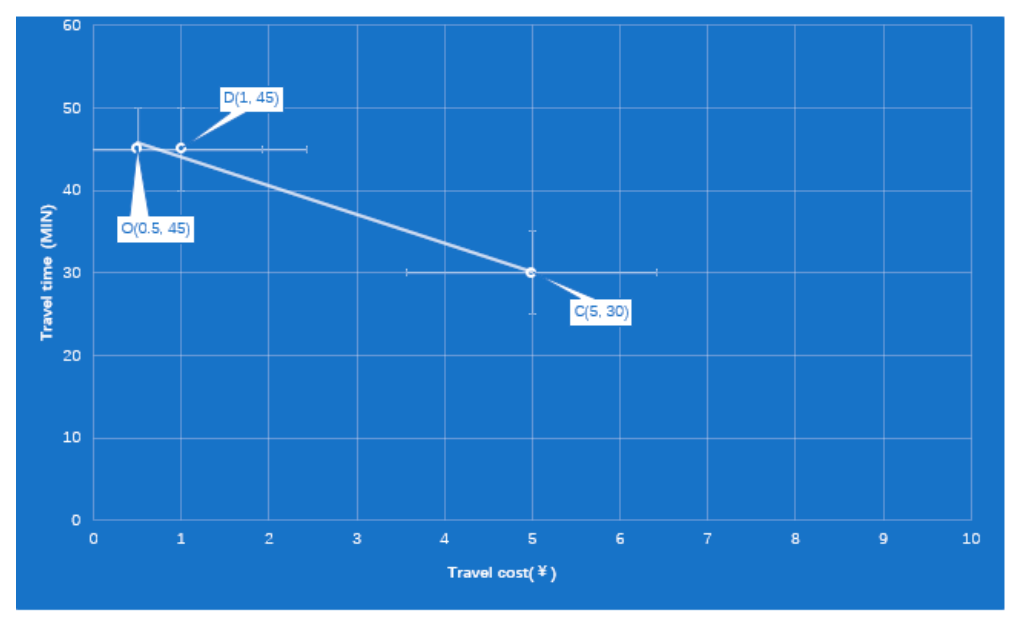

Figure 6. The Decoy Effect.

\subsection{The Mathematical Analysis of an Individual Decoy Effect}

The nature of the decoy effect can be revealed by analyzing a parent's motivation that changes from car to bus after the introduction of the decoy. If $M_{B u s}-M_{C a r}=e$ where $e$ is a parameter and is near 0 . The smaller $e$ is, the easier the parent is affected by the decoy. If $d T$ is used to indicate the difference between a mode's travel time and the average mode's travel time, while $d C$ represent the difference between a mode's travel cost and the average mode's travel cost. One obtains the following equations:

$$
\begin{aligned}
& d T_{\text {Bus }}=T_{\text {Bus }}-T_{\text {ave }}=T_{\text {Bus }}-\left(T_{B u s}+T_{C a r}\right) / 2 \\
& d T_{\text {Car }}=T_{\text {Car }}-T_{\text {ave }}=T_{\text {Car }}-\left(T_{B u s}+T_{\text {Car }}\right) / 2 \\
& d C_{B u s}=C_{B u s}-C_{a v e}=C_{B u s}-\left(C_{B u s}+C_{C a r}\right) / 2 \\
& d C_{\text {Car }}=C_{C a r}-C_{\text {ave }}=C_{C a r}-\left(C_{B u s}+C_{C a r}\right) / 2
\end{aligned}
$$




$$
\begin{aligned}
& M_{\text {Bus }}=\left(-\delta^{d T_{B u s}}+t\right) \times T_{\text {Bus }}+\left(-\lambda^{d C_{\text {Bus }}}+c\right) \times C_{\text {Bus }}+e^{-\beta_{\text {Bus }} D} \times D+\left(1-S^{0.6}\right) \times S_{\text {Bus }}+C R \times S_{\text {social }}(F)_{\text {Bus }} \\
& M_{C a r}=\left(-\delta^{d T_{C a r}}+t\right) \times T_{C a r}+\left(-\lambda^{d C_{C a r}}+c\right) \times C_{C a r}+e^{-\beta_{C a r} D} \times D+\left(1-S^{0.6}\right) \times S_{C a r}+C R \times S_{\text {social }}(F)_{C a r}
\end{aligned}
$$

After the entry of the decoy, $d T^{\prime}$ denote the new difference between a mode's travel time and the average travel time of the mode. $d C^{\prime}$ reveal the new difference between a mode's travel cost and the average travel cost of the mode. $M_{B u s}^{\prime}$ and $M_{C a r}^{\prime}$, the parents' new motivations for bus and car.

$$
\begin{aligned}
& d T_{B u s}^{\prime}=T_{B u s}-\left(T_{B u s}+T_{C a r}+T_{B u s 1}\right) / 3 \\
& d T_{\text {Car }}^{\prime}=T_{\text {Car }}-\left(T_{B u s}+T_{C a r}+T_{B u s 1}\right) / 3 \\
& d C_{B u s}^{\prime}=C_{B u s}-\left(C_{B u s}+C_{C a r}+C_{B u s 1}\right) / 3 \\
& d C_{C a r}^{\prime}=C_{C a r}-\left(C_{B u s}+C_{C a r}+C_{B u s 1}\right) / 3 \\
& M_{\text {Bus }}^{\prime}=\left(-\delta^{d T_{\text {Bus }}^{\prime}}+t\right) \times T_{\text {Bus }}+\left(-\lambda^{d C_{\text {Bus }}^{\prime}}+c\right) \times C_{\text {Bus }}+e^{-\beta_{\text {Bus }}^{\prime} D} \times D+\left(1-S^{0.6}\right) \times S_{\text {Bus }}^{\prime}+C R \times S_{\text {social }}(F)_{\text {Bus }}^{\prime} \\
& M_{C a r}^{\prime}=\left(-\delta^{d T_{C a r}^{\prime}}+t\right) \times T_{C a r}+\left(-\lambda^{d C_{C a r}^{\prime}}+c\right) \times C_{C a r}+e^{-\beta_{C a r}^{\prime} D} \times D+\left(1-S^{0.6}\right) \times S_{C a r}^{\prime}+C R \times S_{\text {social }}(F)_{C a r}^{\prime}
\end{aligned}
$$

Equation (15) minus Equation (13), and Equation (16) minus Equation (14), we can obtains the following equations:

$$
\begin{aligned}
& M_{B u s}^{\prime}-M_{B u s}=\left(\delta^{d T_{B u s}}-\delta^{d T_{B u s}^{\prime}}\right) \times T_{B u s}+\left(\lambda^{d C_{B u s}}-\lambda^{d C_{B u s}^{\prime}}\right) \times C_{B u s}+\left(e^{-\beta_{B u s}^{\prime} D}-e^{-\beta_{B u s} D}\right) \times D \\
& +\left(1-S^{0.6}\right) \times\left(S_{B u s}^{\prime}-S_{B u s}\right)+C R \times\left[S_{\text {social }}(F)_{B u s}^{\prime}-S_{\text {social }}(F)_{B u s}\right] \\
& M_{C a r}^{\prime}-M_{C a r}=\left(\delta^{d T_{C a r}}-\delta^{d T_{C a r}^{\prime}}\right) \times T_{C a r}+\left(\lambda^{d C_{C a r}}-\lambda^{d C_{C a r}^{\prime}}\right) \times C_{C a r}+\left(e^{-\beta_{C a r}^{\prime} D}-e^{-\beta_{C a r} D}\right) \times D \\
& +\left(1-S^{0.6}\right) \times\left(S_{C a r}^{\prime}-S_{C a r}\right)+C R \times\left[S_{\text {social }}(F)_{C a r}^{\prime}-S_{\text {social }}(F)_{C a r}\right]
\end{aligned}
$$

Equation (17) minus Equation (18) results in Equation (19).

$$
\begin{aligned}
& M_{\text {Bus }}^{\prime}-M_{C a r}^{\prime}=\left(\delta^{d T_{B u s}}-\delta^{d T_{B u s}^{\prime}}\right) \times T_{\text {Bus }}-\left(\delta^{d T_{C a r}}-\delta^{d T_{C a r}^{\prime}}\right) \times T_{C a r}+\left(\lambda^{d C_{B u s}}-\lambda^{d C_{B u s}^{\prime}}\right) \times C_{B u s}-\left(\lambda^{d C_{C a r}}-\lambda^{d C_{C a r}^{\prime}}\right) \times C_{C a r}+ \\
& \left(e^{-\beta_{\text {Bus }}^{\prime} D}-e^{-\beta_{\text {Bus }} D}-e^{-\beta_{C a r}^{\prime} D}+e^{-\beta_{\text {Car }} D}\right) \times D+\left(1-S^{0.6}\right) \times\left(S_{\text {Bus }}^{\prime}-S_{\text {Bus }}-S_{\text {Car }}^{\prime}+S_{C a r}\right) \\
& +C R \times\left[S_{\text {social }}(F)_{\text {Bus }}^{\prime}-S_{\text {social }}(F)_{\text {Bus }}-S_{\text {social }}(F)_{\text {Car }}^{\prime}+S_{\text {social }}(F)_{\text {Car }}\right]
\end{aligned}
$$

We can analyze the result of Equation (19). Due to $T_{B u s 1}>T_{\text {ave }}, C_{B u s 1}<C_{\text {avee }}$, then $C_{\text {ave }}^{\prime}\left\langle C_{\text {ave }}, T_{\text {ave }}^{\prime}\right\rangle$ $T_{\text {ave, }}$ the result is $d T_{\text {Bus }}^{\prime}<d T_{\text {Bus }}, d T_{C a r}^{\prime}<d T_{C a r}, d C_{B u s}^{\prime}>d C_{B u s}$ and $d C_{C a r}^{\prime}>d C_{C a r} . \delta^{d T_{B u s}}-\delta^{d T_{\text {Bus }}^{\prime}}>0$, $\delta^{d T_{C a r}}-\delta^{d T_{C a r}^{\prime}}>0$, and $T_{\text {Bus }}>T_{\text {Car }}>0$, therefore, $\left(\delta^{d T_{\text {Bus }}}-\delta^{d T_{B u s}^{\prime}}\right) \times T_{\text {Bus }}-\left(\delta^{d T_{C a r}}-\delta^{d T_{C a r}^{\prime}}\right) \times$ $T_{\text {Car }}>0$. Similarly, $\left(\lambda^{d C_{\text {Bus }}}-\lambda^{d C_{B u s}^{\prime}}\right) \times C_{\text {Bus }}-\left(\lambda^{d C_{C a r}}-\lambda^{d C_{C a r}^{\prime}}\right) \times C_{C a r}>0$.

As the analysis focuses on parents' decoy effect, the model assumes that the decoy's entry does not mathematically change $\beta_{\text {Bus }}, \beta_{\text {Car }}, S_{B u s}, S_{\text {Car }}, S_{\text {social }}(F)_{B u s}$ and $S_{\text {social }}(F)_{\text {Car }}$. We obtains the following equations:

$$
M_{\text {Bus }}^{\prime}-M_{C a r}^{\prime}>0
$$

Thus, from the initial $M_{B u s}<M_{C a r}$ to the current $M_{B u s}^{\prime}>M_{C a r}^{\prime}$, the parent choose escort mode has shifted his/her preference from Car to Bus.

To the best of our knowledge, the decoy effect has been studied in various fields, such as in the fields of psychology, economics, sociology and marketing. However, there is little literature on the decoy effect in transportation field except Guevara and Fukushi [29]. Moreover, most of the literature uses static mathematical model to study decoy effects, this static equation-based analysis includes many assumptions. For example, $e$ is very small, and the entry of the decoy does not change $\beta_{\text {Bus }}, \beta_{\text {Car }}, S_{\text {Bus }}, S_{\text {Car }}, S_{\text {social }}(F)_{\text {Bus }}$ and $S_{\text {social }}(F)_{\text {Car }}$. Actually, the change of parent agent's preference 
is influenced by other people in the social network. Thus, the entry of the decoy on the market does change these parameter. Therefore, the static mathematical model reveals this dynamic process insufficiently. The decoy effect is a dynamically emergent phenomenon that involves the preference changes of a large number of parent agents and their social interactions. By using ABM can capable of further exploring the decoy effect. Therefore, based on the aforementioned agent-based escort mode choice decision model, we simulated the parent escort mode choice with the decoy effect.

\subsection{The Simulation Experiments}

This research programmed the mode choice motivation adjustment function with AnyLogic. In order to simplify the model, we used parent agent's month income to represent all of the parent agents' socio-economic attributes. Parent agent's travel time and cost sensitivity parameters ranged from 0 to 100 and were controlled by the constants $t$ and $c$, on the basis of the parent agent's month incomes.

Many behavioral economists and psychologists framed that "social choice", and pointed out that the individual decision is inevitably influenced by others' actions in social network [27]. The graph of a real world social network is generated using an extremely simple algorithm, according to the model of Watts and Strogatz [30], as shown in Figure 7. When the distance $L$ below $L_{\max }$, each parent agent interacted with other neighborhood agents in the concept space. When the distance $L$ exceeds the limited distance $L_{\max }$, there no linkage exists between parent agents and neighbor agents. $C$ (ContactRate) represents average daily interaction rate. The variable $C$ was ranging from 0 to 0.1 . The random distribution of the time of Car and Bus was between 10 to 100, and the cost of Car and Bus between 0 and 20, as shown in Table 4 .

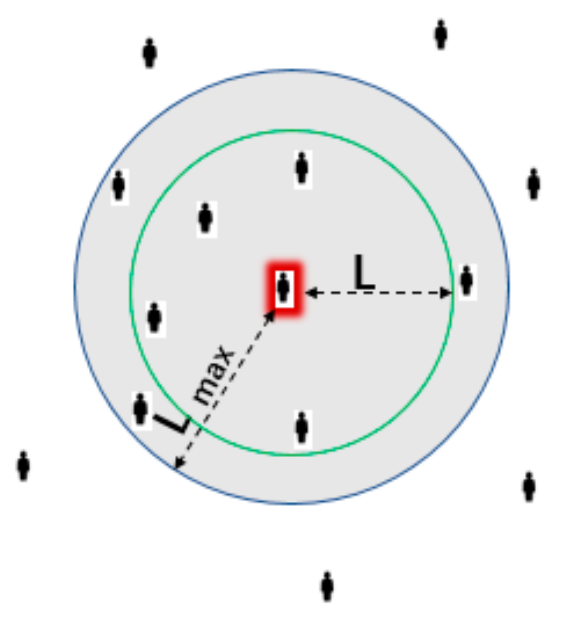

Figure 7. Agents' distribution and interactions.

Table 4. The scale and distribution of variables/parameters in the simulation.

\begin{tabular}{ccc}
\hline Variables/Parameters & Scale & Distribution \\
\hline$t$ & $0-100$ & Depends on parental month income \\
$c$ & $0-100$ & Depends on parental month income \\
$P_{D}$ & $0-1$ & Depends on distance from home to school \\
$\beta$ (DisEffectiveness) & $0-1$ & Depends on distance from home to school \\
$C$ (ContactRate) & $0-0.1$ & Depends on distance of agents \\
$S$ (SafetyEffectiveness) & $0-1$ & Random normal distribution \\
$T_{C A R}$ & $10-60$ (min) & Depends on distance from home to school \\
$C_{C A R}$ & $0-20$ (yuan) & Depends on distance from home to school \\
$T_{B U S}$ & $10-60$ (min) & Depends on distance from home to school \\
$C_{B U S}$ & $0-20$ (yuan) & Depends on distance from home to school \\
\hline
\end{tabular}


Table 4. Cont.

\begin{tabular}{ccc}
\hline Variables/Parameters & Scale & Distribution \\
\hline$T_{D E C O Y}$ & $T_{D E C O Y}=T_{B U S}$ & Random normal distribution \\
$C_{D E C O Y}$ & $C_{C A R}>C_{D E C O Y}>C_{B U S}$ & Random normal distribution \\
$L$ & $0-100$ & Random normal distribution \\
\hline
\end{tabular}

\subsection{Results}

In our simulation, software of AnyLogic based on the rules set in Table 4 randomly picked up values of parameters and variables of each agent. As shown in Figure 8, lavender agent represents those who choose travel mode Car, and yellowgreen agents were those chose who travel mode Bus. The number of parents choosing public transport to escort their children before the decoy entry was 153, accounting for $62.45 \%$. Compare the change of choosing public transport proportion after introducing decoy effect, as shown in Figure 9. The number of parents choosing public transport to escort their children after the decoy entry was 182 , accounting for $74.29 \%$, increased by $11.84 \%$. The simulation results show that the introduction of a decoy into school travel mode caused a substantial shift of preferences. When checking the parameters of the parent agents who switched their preferences, the difference between their motivations for Bus $\left(M_{B u s}\right)$ and their motivations for B $\left(M_{C a r}\right)$ appeared to be very small. At this time external stimuli easily lured these parent agents. Therefore, in transportation system, traffic authority changes in promotional tactics can easily influence this group of parents. This finding is also in line with the hypothesis that $e$ is very small in the equation-based analysis of a parent agent's preference change. However, when checking the parent agents who never switched their preferences, the differences between $M_{B u s}$ and $M_{C a r}$ were very large, so these parent agents were either loyal to Bus or to Car. We conducted further research by changing interaction of radius from $L$ to $L_{\max }$, that is $C R=0.1$. Which can increase the influence that an agent perceives from other agents. The results show that the increase interaction of radius had lured more agents changeable. If one sets the number of interaction of radius exceed $L_{\max }$, the entry of the decoy similar to interaction of $L_{\text {max }}$ radius.
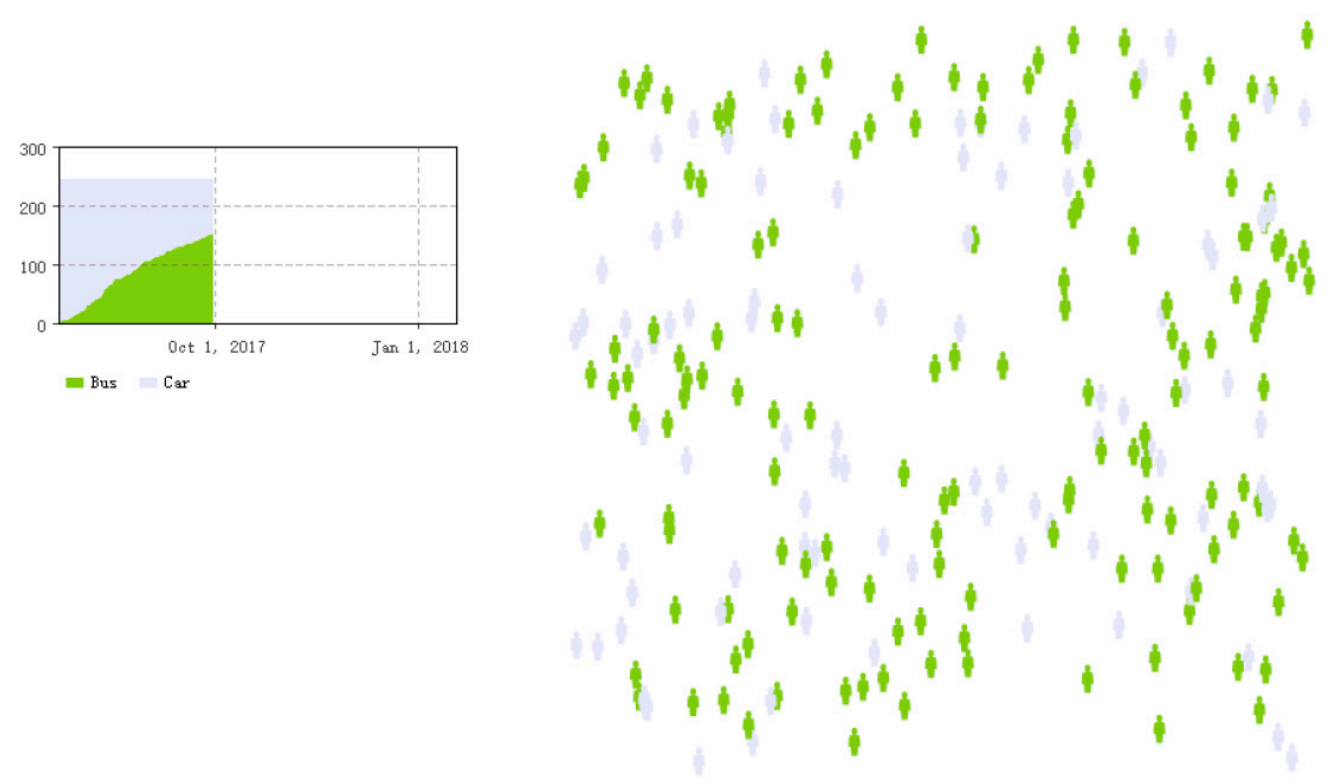

Figure 8. Simulation before the decoy entry. 

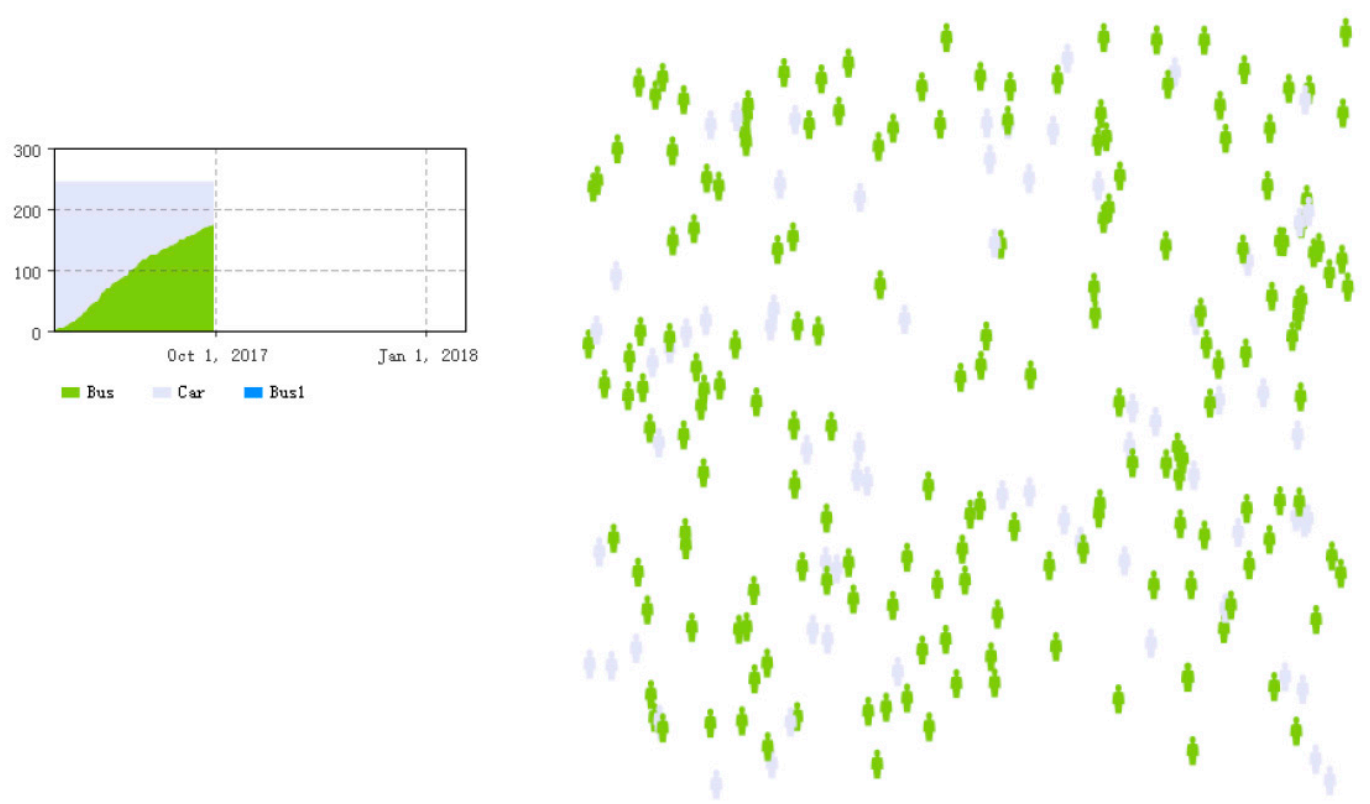

Figure 9. Simulation after the decoy entry.

\section{Conclusions}

Compared with other research in other fields, the agent-based model of parent escort mode choice decision-making and the decoy effect in transportation field that integrates psychology, sociology, and computer science. The traditional economic model may lack robustness, agent-based simulation capability both simulate dynamic social networks in different degrees and to provide more flexible decision frameworks. In order to verify the dynamic nature of parents' escort choices with decoy effect, the kind of agent-based model simulation of parent escort mode choice behavior has been presented. The core of this model is an escort mode choice motivation adjustment function that combines distance, traffic safety and social influence.

In contrast to many previous studies that have only focused on socioeconomic, household and built environment factors in child' mode use in school travel with parental escort decisions. This study examined the relative role of parental motivation factors associated with distance, traffic safety and social influence on children's school travel mode. Before the decoy effect was introduced, the proportion of parents to choose bus escorts was $62.45 \%$. After introducing the decoy effect, the proportion of parents to choose the bus escort increased to $74.29 \%$. Promoting parents use bus escort theirs' children to school could reduce traffic congestion associated with use of car modes in urban settlements.

The limitation of this study is that in order to decrease the complexity of the model, the researchers used income to represent all the agents' socio-economic attributes in the agent-based escort mode choice model. To a certain extent, it reduces the fidelity of the agent. Therefore, in order to establish of an agent-based model of parent escort mode choice behavior with an even higher degree of agent fidelity, it is necessary to solve this limitation.

Author Contributions: Peng Jing conceived, designed the data the experiments; and Qingku You analyzed the data; Long Chen supervised the work; All authors have read and approved the final manuscript.

Conflicts of Interest: The authors declare that they have no conflict of interest.

\section{References}

1. Mcdonald, N.C. Children's Travel: Patterns and Influences. Available online: https:/ / escholarship.org/uc/ item/51c9m01c (accessed on 24 February 2018). 
2. Yarlagadda, A.K.; Srinivasan, S. Modeling children's school travel mode and parental escort decisions. Transportation 2008, 35, 201-218. [CrossRef]

3. Faulkner, G.E.J.; Buliung, R.N.; Flora, P.K.; Fusco, C. Active school transport, physical activity levels and body weight of children and youth: A systematic review. Prev. Med. 2009, 48, 3. [CrossRef] [PubMed]

4. Fusco, C.; Moola, F.; Faulkner, G.; Buliung, R.; Richichi, V. Toward an understanding of children's perceptions of their transport geographies: (Non)active school travel and visual representations of the built environment. J. Transp. Geogr. 2012, 20, 62-70. [CrossRef]

5. He, S.Y.; Giuliano, G. Factors affecting children's journeys to school: A joint escort-mode choice mode. Transportation 2017, 44, 199-224. [CrossRef]

6. Zhang, R.; Yao, E.; Liu, Z. School travel mode choice in Beijing, China. J. Transp. Geogr. 2017, 62, 98-110. [CrossRef]

7. Shi, J.; Jian, M.; Zhang, W. Research on the influence of student motor vehicle on Beijing road traffic. J Wuhan Univ. Technol. 2014, 5, 960-964.

8. Leslie, E.; Kremer, P.; Toumbourou, J.W.; Williams, J.W. Gender differences in personal, social and environmental influences on active travel to and from school for Australian adolescents. J Sci. Med. Sport 2010, 13, 597-601. [CrossRef] [PubMed]

9. Ermagun, A.; Samimi, A. How Are Children Accompanied to School? J. Urban Plan. Dev. 2016, 142, 04016002. [CrossRef]

10. Wets, G.; Zwerts, E. Children's Travel Behavior: World of Difference. In Proceedings of the Transportation Research Board 85th Annual Meeting, Washington, DC, USA, 22-26 January 2006.

11. Nelson, N.M.; Foley, E.; O'Gorman, D.J.; Moyna, N.M.; Woods, C.B. Active commuting to school: How far is too far? Int. J. Behav. Nutr. Phys. Act. 2008, 5, 1. [CrossRef] [PubMed]

12. Mehdizadeh, M.; Nordfjaern, T.; Mamdoohi, A.R.; Mohaymany, A.S. The role of parental risk judgements, transport safety attitudes, transport priorities and accident experiences on pupils' walking to school. Accid. Anal. Prev. 2017, 102, 60-71. [CrossRef] [PubMed]

13. Hsu, H.P.; Saphores, J.D. Impacts of parental gender and attitudes on children's school travel mode and parental chauffeuring behavior: Results for California based on the 2009 National Household Travel Survey. Transportation 2014, 41, 543-565. [CrossRef]

14. Liu, S.; Murray-Tuite, P.; Schweitzer, L. Analysis of child pick-up during daily routines and for daytime no-notice evacuations. Transp. Res. Policy Pract. 2012, 46, 48-67. [CrossRef]

15. Ermagun, A.; Levinson, D. Intra-household bargaining for school trip accompaniment of children: A group decision approach. Transp. Res. Policy Pract. 2016, 94, 222-234. [CrossRef]

16. Susilo, Y.O.; Liu, C. The influence of parents' travel patterns, perceptions and residential self-selectivity to their children travel mode shares. Transportation 2016, 43, 357-378. [CrossRef]

17. Macal, C.M.; North, M.J. Agent-based modeling and simulation. In Proceedings of the Winter Simulation Conference, Austin, TX, USA, 13-16 December 2009; pp. 86-98.

18. Han, Q.; Arentze, T.; Timmermans, H.; Janssens, D.; Wets, G. The effects of social networks on choice set dynamics: Results of numerical simulations using an agent-based approach. Transp. Res. 2011, 45, 310-322. [CrossRef]

19. Yang, Y.; Diez-Roux, A.V. Using an agent-based model to simulate children's active travel to school. Int. J. Behave. Nutr. Phys. Act. 2013, 10, 67. [CrossRef] [PubMed]

20. Yang, Y.; Roux, A.V.D.; Auchincloss, A.H.; Rodriguez, D.A.; Brown, D.G. A spatial agent-based model for the simulation of adults' daily walking within a city. Am. J. Prev. Med. 2011, 40, 353-361. [CrossRef] [PubMed]

21. Yang, Y.; Diez-Roux, A.; Evenson, K.R.; Colabianchi, N. Examining the impact of the walking school bus with an agent-based model. Am. J. Public Health 2014, 104, 1196-1203. [CrossRef] [PubMed]

22. Ajzen, I. The theory of planned behavior. Br. J. Soc. Psychol. 1991, 14, 137. [CrossRef]

23. Petty, R.E.; Wegener, D.T.; Fabrigar, L.R. Attitudes and attitude change. Annu. Rev. Psychol. 2010, 48, 479-523. [CrossRef] [PubMed]

24. Mcclelland, D.C. Human Motivation; Cambridge University Press: Cambridge, UK, 1987.

25. Kamargianni, M.; Dubey, S.; Polydoropoulou, A.; Bhat, C. Investigating the subjective and objective factors influencing teenagers' school travel mode choice--An integrated choice and latent variable model. Transp. Res. Policy Pract. 2015, 78, 473-488. [CrossRef] 
26. Davison, K.K.; Werder, J.L.; Lawson, C.T. Peer reviewed: Children's active commuting to school: Current knowledge and future directions. Prev. Chronic Dis. 2008, 5, A100. [PubMed]

27. Sunitiyoso, Y. Social Interaction in Travel Behaviour: Insights for Developing Effective Travel Demand Management for Indonesia. Syst. Sci. Complex Policy Mak. 2016, 65-91. [CrossRef]

28. McFadden, D. Sociality, rationality, and the ecology of choice. In Choice Modelling: The State-of-the-Art and the State-of-Practice: Proceedings from the Inaugural International Choice Modelling Conference; Emerald Group Publishing: Bradford, UK, 2010; pp. 1-17.

29. Guevara, C.A.; Fukushi, M. Modeling the decoy effect with context-RUM Models: Diagrammatic analysis and empirical evidence from route choice SP and mode choice RP case studies. Transp. Res. Methodol. 2016, 93, 318-337. [CrossRef]

30. Watts, D.J.; Strogatz, S.H. Collective dynamics of 'small-world' networks. Nature 1998, 393, 440. [CrossRef] [PubMed]

(C) 2018 by the authors. Licensee MDPI, Basel, Switzerland. This article is an open access article distributed under the terms and conditions of the Creative Commons Attribution (CC BY) license (http://creativecommons.org/licenses/by/4.0/). 